\title{
Molecular markers of sulfadoxine-pyrimethamine resistant malaria prior to intermittent preventive treatment among pregnancies in Makurdi, Nigeria
}

\author{
Terwase Fabian IKPA ${ }^{1,4 *}$, Kiliobas Kiri SHA' $A^{2,4}$ and Ishaya Kato AUTA ${ }^{3,4}$ \\ ${ }^{I}$ Department of Wildlife University of Agriculture, Makurdi, PMB 2373 Makurdi, Nigeria. \\ ${ }^{2}$ Department of Science Laboratory Technology, College of Science and Technology, Adamawa State \\ Polytechnic, PMB 2146 Yola, Nigeria. \\ ${ }^{3}$ Department of Science Laboratory Technology Federal Polytechnic Nasarawa, PMB 01 Nasarawa Nigeria. \\ ${ }^{4}$ Department of Zoology, University of Jos, PMB 2084 Jos, Nigeria. \\ *Corresponding author; E-mail: terwasefsi@yahoo.com; tfikpa@gmail.com
}

\begin{abstract}
Molecular markers of sulfadoxine-pyrimethamine (SP) resistance were monitored in pregnant women of mean age $28 \pm$ 11years in Makurdi, Nigeria. A total of 82 Plasmodium falciparum malaria positive blood samples were obtained prior to commencement of intermittent preventive treatment with SP (IPT $\left.\mathrm{p}_{\mathrm{p}} \mathrm{SP}\right)$ during antenatal visits. Of the 82 samples, 71 were successfully genotyped at the dihydrofolate reductase ( $d h f r)$ loci 51, 59, 108 and 164; and dihydropteroate synthase (dhps) loci 436, 437, and 540. The genotyping was accomplished by means of polymerase chain reaction, and restriction fragment length polymorphisms. The aim was to determine the percentage frequencies of $P$. falciparum single nucleotide polymorphisms (SNPs) associated with resistance to SP in vivo. The results show that both the dhfr and dhps genes each produced 5 different haplotypes with varying percentage frequencies. All genotyped gene loci had SNPs except $d h f r 164$ and dhps 540. Haplotype combination of dhfr/dhps alleles yielded 15 different genotypes of P. falciparum parasites. The combined frequencies of triple/quadruple mutant haplotypes associated with in vivo SP resistance was $35.21 \%$, but was significantly lower than single/double mutant haplotypes not associated with SP resistance $\left(\chi^{2}=6.21, \mathrm{df}=1, \mathrm{p}=0.01\right)$. These results suggest a possible rise in in vivo $\mathrm{SP}$ resistance during $\mathrm{IPT}_{\mathrm{P}}$-SP. There is a need for continuous monitoring of SP efficacy, for effective intermittent preventive treatment with the drug in the area.
\end{abstract}

(C) 2014 International Formulae Group. All rights reserved.

Keywords: Malaria, antimalarial drug resistance, single nucleotide polymorphisms, haplotype.

\section{INTRODUCTION}

The synergistic antifolate drug combination, sulfadoxine-pyrimethamine (SP) has played a critical role in the prevention and control of malaria since the late 1980s. This role was immensely appreciated particularly when it became evidently clear that resistance to chloroquine was extensive (Warhust, 2001) and the latter drug could not be relied upon as a drug of choice for the treatment of malaria as it had been the case in the past (WHO, 2005). However, it was a matter of time before widespread resistance to SP appeared in many parts of the world 
(Sibley et al., 2001; White, 2004). To date, despite huge evidence of falciparum malaria resistance to SP, its relevance in the intermittent preventive treatment of malaria in pregnancy $\left(\mathrm{IPT}_{\mathrm{P}}\right.$ ) is justified by lack of a better alternative drug to serve the same purpose (Vallely et al., 2007; WHO, 2010; WHO, 2013). Apart from its recommended use in the IPT $\mathrm{IP}_{\mathrm{P}}$ the drug has also been recommended in combination with artesunate for the treatment of malaria in areas like the West African sub region, where resistance to the drug is comparably lower to other regions like South East Asia, South America, or East Africa (WHO, 2010). Thus in areas where $P$. falciparum resistance to the drug appears to be less wide spread, the continuous molecular survey of single nucleotide polymorphisms (SNPs) associated with decreasing sensitivity of the malaria parasites to SP in vivo is very relevant (Molecular Module WWARN, 2011). This is necessary in order to assess the continued relevance of SP as an antimalarial drug in the area of interest, among the groups that rely on it.

In Nigeria, SP is commonly available over the counter in both rural and urban areas at patent medicine stores (Okeke et al., 2006). Because of its cheaper cost compared to artemether/lumefantrine, SP is still being used by many people as a single dose therapy for self treatment of suspected cases of acute malaria infections (Omole and Onademuren, 2010). This negates the main purpose for which the drug is currently recommended (WHO, 2013). The practice is particularly common among patent medicine vendors who often prescribe and vend various brands of SP available in their drug stores, for the treatment of any symptoms of diseases that resembles malaria (Okeke et al., 2006). Of particular interest to this study is the recommendation for the intermittent preventive treatment of malaria with SP in pregnancy ( $\mathrm{IPT}_{\mathrm{P}} \mathrm{SP}$ ), for the control of malaria (WHO, 2013) and the reduction of its adverse effects, during the period of pregnancy (Moussiliou et al., 2013; Tan et al., 2014). However, it has been shown that in areas with a known history of wide spread drug resistance, IPT $_{\mathrm{P}}-\mathrm{SP}$ may not confer benefit during the period of pregnancy (Harrington et al., 2011).

In order to determine how relevant SP may be for its recommended purpose among pregnancies in some Nigerian women, we decided to survey the frequency distribution of SNPs in the dihydrofolate reductase ( $d h f r)$ and dihydropteroate synthase (dhps) genes of $P$. falciparum parasites among pregnant women in Makurdi. These were women who had started their antenatal visits, but had not yet been administered any dose of SP. The aim was to determine whether prior to the start of IPT $_{\mathrm{P}}-\mathrm{SP}$ beginning from the second trimester of pregnancy, molecular markers of in vivo $P$. falciparum resistance to SP were already pre-expressed among these pregnancies. Especially if the levels were such that could further compromise curative doses of SP that were to be subsequently administered, beginning from the $16^{\text {th }}$ week of the gestation period.

\section{MATERIALS AND METHODS \\ Study area}

Samples for this study were collected at the Bishop Murray Medical Centre, and the Federal Medical Centre. Both medical facilities are located in Makurdi, north central Nigeria. Ethical approval was obtained from each hospital.

\section{Subjects and blood sample collection}

Blood samples were collected from pregnant women attending antenatal clinics, aged 18-38 years. The mean age of subjects was $28 \pm 11$ years; each subject's consent was sought and obtained after the purpose of the study was explained to each of them. Among the subjects, the inclusion criteria included those whose gestation period were below 16 weeks either from known knowledge of scan results or last menstrual period, and had denied taking any antimalarial drug during the period of pregnancy. During blood sample collection, a few drops of finger prick blood 
from each participant were squeezed on a prelabeled piece of Whatman 3MM filter paper, allowed to air dry and preserved in an air tight container with silica gel. A further single drop of blood from the same subject was also spotted twice on an identically labeled clean microscopy slide for both thick and thin blood films preparation. The air dried thick blood films were stained with $10 \%$ Giemsa solution for 10 minutes, and screened under the microscope for the presence of malaria parasites. Slides with parasite density of $\geq$ 2500 parasites $/ \mu 1$ of blood were further identified to species level using thin blood films stained with $2.5 \%$ Giemsa stain for 45 minutes. A total of 82 malaria positive slides were matched with their corresponding blood soaked filter papers, which were then selected for malaria parasite DNA extraction. Sample collection lasted from April 2008 to April 2009.

\section{Parasite DNA extraction}

Parasite DNA was extracted from approximately $3 \mathrm{~mm}^{2}$ piece of blood blotted filter paper, using standard methanolfixation/heat extraction procedure (Djimde et al., 2001). A $5 \mu$ l solution of the DNA was used as template for nested polymerase chain reaction (PCR) in a total reaction volume mixture of $25 \mu 1$.

\section{PCR amplification of $\boldsymbol{d h f r}$ and $\boldsymbol{d h p s}$ genes}

Parasite DNA was amplified for detection of SNPs in the dhfr and dhps genes by nested PCR using published primers (Duraisingh et al., 1998). The PCR was performed on PTC 200 Peltier thermal cycler. The primary reaction was 45 cycles for both dhfr/dhps genes with these conditions: primary denaturation of DNA at $94{ }^{\circ} \mathrm{C}$ for 3 minutes, strands separation at $94{ }^{\circ} \mathrm{C}$ for 1 minute, primers annealing temperature of 50 ${ }^{\circ} \mathrm{C}$ for 2 minutes, Taq polymerase DNA synthesis at $72{ }^{\circ} \mathrm{C}$ for 2 minutes, and final primers extension at $72{ }^{\circ} \mathrm{C}$ for 15 minutes. Similar conditions were applicable to the secondary amplification of 35 reaction cycles for both genes except that, the annealing temperature for the primers was reduced to 45 ${ }^{\circ} \mathrm{C}$ for 2 minutes, while the final primers extension time was also reduced to 10 minutes at $72{ }^{\circ} \mathrm{C}$. A total of 71 of 82 samples $(86.59 \%)$ were successfully amplified.

\section{Enzyme restriction digestion of $d h f r$ and dhps amplicons}

A $5 \mu \mathrm{l}$ volume of the secondary PCR products from each test sample was digested with a recommended restriction enzyme, from New England Biolabs using the restriction fragment length polymorphisms (RFLP) procedure (Duraisingh et al., 1998; Kublin et al., 2002). Appropriate recommended restriction enzymes were used in order to detect the various SNPs at $d h f r$ and dhps codons. In each case, the secondary reaction product of PCR, and the enzyme were incubated overnight at a specific temperature, based on standard protocols (Duraisingh et al., 1998). Digested parasite DNA fragments were separated on $2 \%$ agarose gel electrophoresis.

\section{Separation of enzyme digests on agarose gel electrophoresis}

The fragments formed by enzyme digestion were separated on $2 \%$ agarose gel electrophoresis together with DNA molecular size markers in TAE buffer. The gels were stained with ethidium bromide and photographed under UV light for visual inspection of fragment sizes (Duraisingh et al., 1998; Kubin et al., 2002). All the 71 amplified DNA fragments were digested and analysed at $d h f r$ codons 51, 59, 108, 164 and dhps codons 436, 437, and 540. Direct counting of SNPs was performed (Hastings et al., 2010) and codons with mixed alleles (wild type/mutant) were classified as mutants. Haplotypes were classified based on a slight modification of the Molecular Module, WWARN (2011). The SNP on dhps 436 was classified as an alternative wild type (Basco and Ringwald, 1998; Nzila, 2000). Thus fragments bearing both dhps 436A and 437G were not classified as double mutants. 


\section{Statistical analysis}

The frequency of haplotypes was expressed as percentages. The total number of haplotypes with less than three dhfr SNPs which could be cleared by SP treatment in vivo was compared with those with at least three dhfr SNPs or more at the dhps that could potentially resist SP treatment in vivo using the chi-square test. The test was performed with SPSS version 20 IBM Inc. The level of significance was set as $\mathrm{P} \leq 0.05$.

\section{RESULTS}

Tables 1 and 2 each shows the percentage frequencies of $P$. falciparum $d h f r$ and dhps haplotypes respectively, from the successfully amplified DNA fragments of the malaria parasites. Only $4.23 \%$ of the malaria parasites had wild type haplotypes at $d h f r$. Another $39.43 \%$ had only one SNP at $d h f r$ 108. This codon was highly mixed with wild type and mutant alleles. The remaining $56.34 \%$ of the parasites had at least two SNPs at $d h f r 51,59$, or 108 that are associated with pyrimethamine resistance, either in mixed or pure form. However, there was no haplotype bearing the $\mathrm{I} 164 \mathrm{~L}$ mutant in the parasite population. In all, 5 different haplotypes were identified at the dhfr. Similarly, at the dhps loci, $4.23 \%$ of the malaria parasites had wild type alleles based on dhps 436, 437, and 540 . The remaining $95.77 \%$ had acquired at least one of the SNPs associated with resistance to sulfadoxine. The K540E mutant was also not seen among the 5 different haplotypes that were observed. Two cases of wild type and mutant allele mixtures were observed at the dhps codon 436. This was a huge contrast compared to the $d h f r$ where majority of the parasites were mixed at codon 108. Haplotypes with SNPs at both $d h f r 436$ and 437 were classified as single mutant (Table 2) since $436 \mathrm{~A}$ was considered an alternative wild type.

The combination of both dhfr and dhps haplotypes produced 15 different genotypes. However, none of these was a wild type (Table 3). Triple mutant $d h f r$ haplotypes with, or without additional mutations at the dhps gene which are mostly associated with resistance to SP in vivo accounted for $35.23 \%$ of the parasites (Figure 1); either as pure or mixed forms. There was a significant difference $\left(\chi^{2}=6.21\right.$, df $\left.=1, \mathrm{P}=0.01\right)$ between the total number of parasites with less than triple mutant haplotypes, compared to the combined number of triple/quadruple mutant haplotypes, based on the chi-square test.

Table 1: Haplotypes of P. falciparum dhfr gene in Makurdi.

\begin{tabular}{lcccclc}
\hline N51I & C59R & S108N & I164L & Type & n & \% Frequency \\
\hline N & C & S & I & wild type & 3 & 4.23 \\
N & C & S/N & I & mixed single mutant & 28 & 39.43 \\
N & $\mathrm{R}$ & S/N & I & Mixed double mutant & 15 & 21.13 \\
I & $\mathrm{R}$ & $\mathrm{N}$ & I & pure triple mutant & 5 & 7.04 \\
I & $\mathrm{R}$ & $\mathrm{S} / \mathrm{N}$ & $\mathrm{I}$ & mixed triple mutant & 20 & 28.17 \\
\hline
\end{tabular}

Table 2: Haplotypes of $P$. falciparum dhps gene in Makurdi.

\begin{tabular}{lccclc}
\hline S436A* & A437G & K540E & Type & $\boldsymbol{n}$ & \% Frequency \\
\hline S & A & K & wild type & 3 & 4.23 \\
A & A & K & alternative wild type & 21 & 29.58 \\
S & G & K & Single mutant & 36 & 50.70 \\
S/A & G & K & mixed single mutant & 2 & 2.82 \\
A & G & K & single mutant & 9 & 12.67 \\
\hline$*$ alternative wild type allele. & & &
\end{tabular}


Table 3: Genotypes of P. falciparum dhfr/dhps genes in Makurdi.

\begin{tabular}{lcccccc}
\hline N51I & C59R & S108N & S436A* & A437G & $\boldsymbol{n}$ & \% Frequency \\
\hline $\mathrm{N}$ & $\mathrm{C}$ & $\mathrm{S}$ & $\mathrm{S}$ & $\mathrm{G}$ & 3 & 4.23 \\
$\mathrm{~N}$ & $\mathrm{R}$ & $\mathrm{S} / \mathrm{N}$ & $\mathrm{A}$ & $\mathrm{G}$ & 2 & 2.83 \\
$\mathrm{~N}$ & $\mathrm{R}$ & $\mathrm{S} / \mathrm{N}$ & $\mathrm{A}$ & $\mathrm{A}$ & 5 & 7.04 \\
$\mathrm{~N}$ & $\mathrm{R}$ & $\mathrm{S} / \mathrm{N}$ & $\mathrm{S}$ & $\mathrm{G}$ & 8 & 11.26 \\
$\mathrm{~N}$ & $\mathrm{C}$ & $\mathrm{S} / \mathrm{N}$ & $\mathrm{A}$ & $\mathrm{A}$ & 11 & 15.49 \\
$\mathrm{~N}$ & $\mathrm{C}$ & $\mathrm{S} / \mathrm{N}$ & $\mathrm{A}$ & $\mathrm{G}$ & 2 & 2.82 \\
$\mathrm{~N}$ & $\mathrm{C}$ & $\mathrm{S} / \mathrm{N}$ & $\mathrm{S}$ & $\mathrm{A}$ & 1 & 1.40 \\
$\mathrm{~N}$ & $\mathrm{C}$ & $\mathrm{S} / \mathrm{N}$ & $\mathrm{S}$ & $\mathrm{G}$ & 12 & 16.90 \\
$\mathrm{~N}$ & $\mathrm{C}$ & $\mathrm{S} / \mathrm{N}$ & $\mathrm{S} / \mathrm{A}$ & $\mathrm{G}$ & 2 & 2.82 \\
$\mathrm{I}$ & $\mathrm{R}$ & $\mathrm{N}$ & $\mathrm{A}$ & $\mathrm{G}$ & 3 & 4.23 \\
$\mathrm{I}$ & $\mathrm{R}$ & $\mathrm{N}$ & $\mathrm{S}$ & $\mathrm{G}$ & 2 & 2.82 \\
$\mathrm{I}$ & $\mathrm{R}$ & $\mathrm{S} / \mathrm{N}$ & $\mathrm{A}$ & $\mathrm{A}$ & 5 & 7.04 \\
$\mathrm{I}$ & $\mathrm{R}$ & $\mathrm{S} / \mathrm{N}$ & $\mathrm{S}$ & $\mathrm{G}$ & 11 & 15.49 \\
$\mathrm{I}$ & $\mathrm{R}$ & $\mathrm{S} / \mathrm{N}$ & $\mathrm{A}$ & $\mathrm{G}$ & 2 & 2.82 \\
$\mathrm{I}$ & $\mathrm{R}$ & $\mathrm{S} / \mathrm{N}$ & $\mathrm{S}$ & $\mathrm{A}$ & 2 & 2.82 \\
\hline
\end{tabular}

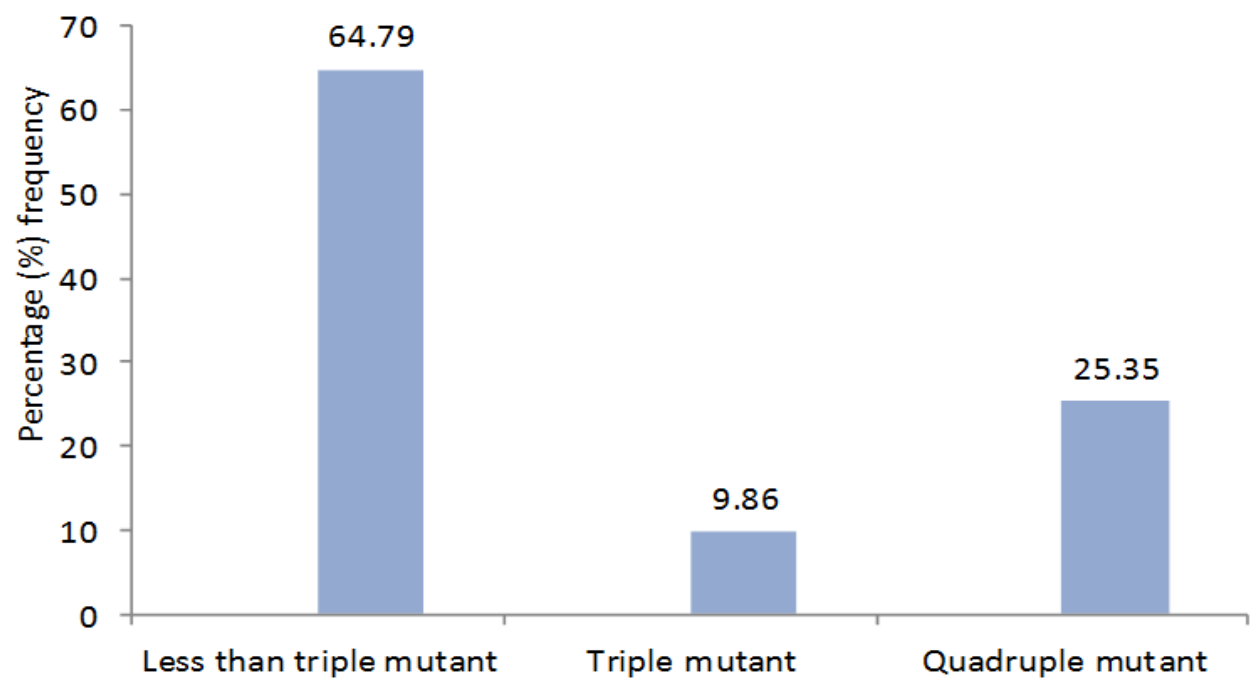

Figure 1: Profile of $P$. falciparum $\mathrm{dhfr} / \mathrm{dhps}$ mutant haplotypes among pregnancies in Makurdi.

\section{DISCUSSION}

Just before the Federal Ministry of Health in Nigeria migrated from malaria monotherapy to the ACTs, the primary drug for the treatment of uncomplicated malaria was the antifolate antimalarial drug SP, which replaced chroloquine as the drug of choice for the treatment of the disease. This replacement was evidenced based as resistance to the latter drug had reached unacceptable levels (Oguche et al., 2004). Although the shift to ACTs has been achieved, SP monotherapy is still common in Nigeria both in rural and urban areas (Okeke et al., 2006; Omole and Onademuren, 2010). The use of the drug as malaria monotherapy, even in recent times is commonly promoted by patent medicine vendors, who employ presumptive diagnosis 
and treatment of clinical malaria among patients that patronize them. This is in addition to its main role as drug to be administered for $\mathrm{IPT}_{\mathrm{P}}$ during the period of pregnancy, in line with current recommendations (WHO, 2010; WHO, 2013). Thus, the unquestionable relevance of SP, whether as a mono or a combination therapy against malaria in Nigeria, and its importance in $\mathrm{IPT}_{P}$ among pregnant women, calls for frequent monitoring of its efficacy. This is needed especially in virgin areas, where such data are not readily available. Therefore, this surveillance study among pregnant women, who were scheduled to start $\mathrm{IPT}_{\mathrm{P}}-\mathrm{SP}$, became necessary to ascertain whether the expression of mutant haplotypes of $P$. falciparum, as markers of SP resistance, prior to the start of $\mathrm{IPT}_{\mathrm{P}}$ would be capable of rendering their subsequent treatment with SP ineffective, for malaria control in pregnancy.

Our data suggest that approximately $35 \%$ of the $P$. falciparum parasites, recovered from our study subjects harboured triple/quadruple mutant haplotypes. They were therefore more likely to develop resistance to SP during treatment. However, this seemingly large proportion of the parasites that potentially could resist treatment to SP was significantly less than the nearly $65 \%$ of parasites with less than a triple SNPs that could be cleared by the drug in vivo (Kublin et al., 2002; Djimde et al., 2008; Tan et al., 2014). Sulfadoxine/pyrimethamine could still be very useful for the purpose of $\mathrm{IPT}_{\mathrm{P}}$ among our subjects in the study area, provided that at the start of IPT $_{\mathrm{P}}-\mathrm{SP}$, the drug should be able to reduce in vivo, the less than triple mutant haplotypes along with a significant portion of the triple/quadruple mutant parasites. For instance, the composition of triple/quadruple mutant haplotypes indicated that only $7.04 \%$ was pure quadruple mutants. The remaining $28.17 \%$ was made up of $9.86 \%$ mixed triple mutant and $18.31 \%$ mixed quadruple mutant haplotypes. The presence of mixed haplotypes could imply two possibilities during actual treatment. First, mutant alleles could revert to wild type (Nzila et al., 2000) and may be cleared by the drug in vivo, thus ensuring that the actual parasite resistance to SP in the sampled population of pregnant women may be lower than $35.21 \%$. A second alternative could be that in the face of actual treatment, wild type alleles would further mutate to mutant alleles, with SP unable to clear the parasites. This would increase in vivo resistance to the drug beyond $35 \%$ and may further reduce the benefits that would have accrued to the subjects (Harrington et al., 2011). Rather than the first possibility, there is ample evidence to support the fact that because of the current level of resistance to the drug, SP treatment in most cases increases the level of mutant alleles, compared to that seen in pre-treatment samples (Nzila et al., 2000; Djimde et al., 2008). Perhaps, the absence of quintuple mutant haplotype as a result of lack of dhfr 164L and dhps 540E in our samples could be that true resistance to SP among pregnant women in Makurdi may be lower than the value observed in our present study. However, no previous related data on SP treatment exist in our sample location, for proper comparison to be made. The lack of the dhfr 164L mutant haplotype in the present study is similar to the findings by Happi et al. (2005) in a sampled population of both pretreatment, and SP treated patients in South Western Nigeria. Given the fact that dhps 540E haplotype was also not detected in this study, dhps $437 \mathrm{G}$ with a frequency of $66.20 \%$ was the only dhps allele, that in combination with triple mutant $d h f r$ haplotypes could increase the overall parasite resistance to SP in vivo. The 436A SNP did occurred in our sample but in Africa, its overall contribution to SP resistance may be less important than the $437 \mathrm{G}$ and the $540 \mathrm{E}$ double mutant haplotypes (Nzila et al., 2000). The later was completely absent, which effectively meant that only quadruple mutant haplotypes at most were seen in our sample. In some parts of Africa, there are reports that even in the presence of very high penetration of the quintuple mutant haplotype; IPT $_{\mathrm{P}}-\mathrm{SP}$ was found to be very useful in reducing the adverse impact of malaria, during the period of pregnancy (Gutman et al., 2013; Tan et al., 2014). On the other hand there are some data that support the view that SP may not confer 
benefits in $\mathrm{IPT}_{\mathrm{P}}$, in an area of wide spread antimalarial drug resistance (Harrington et al., 2011; Mossiliou et al., 2013). Our data although, not a direct observation in the course of SP treatment hints to a possible rise in the level of resistance markers that may render in vivo treatment with $\mathrm{SP}$ rather ineffective in the course of actual treatment with the drug.

Would such ineffective treatment completely abolish the benefits that would have accrued to the pregnancies assuming SP were to be very effective? No; SP may continue to be beneficial for the purpose of $\mathrm{IPT}_{\mathrm{P}}$ because even in a presumably worst case scenario where quintuple mutant haplotype had $100 \%$ penetration, treatment with the drug significantly reduced adverse effects of malaria on pregnancies (Gutman et al., 2013; Tan et al., 2014). Thus given that the quintuple mutant haplotype is less likely to be found in our study area during actual treatment with SP; it could be that perhaps, on a comparative basis, IPT $_{\mathrm{P}}$-SP may be more beneficial to our study population, compared to areas where the quintuple mutant haplotype already existed on a greater scale.

Our study was narrowly confined, to investigating the molecular evidence that suggests SP resistance prior to the beginning of $\mathrm{IPT}_{\mathrm{P}}-\mathrm{SP}$, and our evidence was based on a rather small sample size. Accordingly, we encourage further surveillance involving a larger sample size that would include similar category of subjects we have studied presently. In addition, those receiving IPT $_{\mathrm{P}^{-}} \mathrm{SP}$ should be included in the same study as well. This will facilitate better comparison to enable us elucidate the true level of SP resistance, and its consequences on pregnancies in our study area, and other similar locations.

\section{ACKNOWLEDGMENTS}

We wish to thank the women who agreed to participate in this study. We also wish to thank all the staff of Bishop Murray Medical Centre and the Federal Medical Centre Makurdi who assisted with sample collection.

\section{REFERENCES}

Basco IK, Ringwald P. 1998. Molecular epidemiology of malaria in Yaounde Cameroon II. Baseline frequency of point mutations in dihydropteroate synthase gene of Plasmodium falciparum. Am. J. Trop. Med. Hyg., 58: 374-377.

Djimde A, Doumbo OK, Cortese JF, Kayentao K, Doumbo S, Diourte Y, Dicko A, Su X, Nomura T, Fidock DA, Wellems TE, Plowe CV. 2001. A molecular marker for chloroquine resistant falciparum malaria. N. Engl. J. Med., 344: 257-263.

Djimde AA, Fofana B, Sagara I, Sidibe B, Toure S, Dembele D, Dama S, Ouologuem D, Dicko A, Doumbo OK. 2008. Efficacy, safety and selection of molecular markers of drug resistance by two ACTs in Mali. Am. J. Trop. Med. Hyg., 78(3): 455-461.

Duraisingh MT, Curtis J, Warhurst DC. 1998. Plasmodium falciparum detection of polymorphism in the dihydrofolate reductase and drihydropteroate synthase gene by polymerase chain reaction and restriction digestion. Exp. Parasitol., 89(1): $1-8$.

Gutman J, Mwandama D, Wiegand RE, Ali D, Mathanga DP, Skarbinski J. 2013. Effectiveness of intermittent preventive treatment with sulfadoxinepyrimethamine during pregnancy on maternal and birth outcomes in machinga district, Malawi. J. Infect. Dis., 208: 907916.

Happi CT, Gbotosho GO, Folarin OA, Akinboye DO, Yusuf BO, Ebong OO, Sowunmi A, Kyle DE, Milhous W, Wirth DF, Oduola AMJ. 2005. Polymorphisms in Plasmodium falciparum dhfr and dhps genes and age related in vivo sulfadoxinepyrimethamine resistance in malarialinfected patients from Nigeria. Acta Trop., 95: 183-193.

Harrington WE, Mutabingwa TK, Kabyemela E, Fried M, Duffy PE. 2011. Intermittent treatment to prevent pregnanacy malaria does not confer benefit in an area of 
widespread drug resistance. Clin. Infect. Dis., 53: 224-230.

Hastings IM, Nsanzabana C, Smith TA. 2010. A comparison of methods to detect and quantify markers of antimalarial drug resistance. Am. J. Trop. Med. Hyg., 83(3): 489-495.

Kublin JG, Dzinjalamala FK, Kamwendo DD, Malkin EM, Cortese JF, Martino LM, Mukadam RA, Rogerson SJ, Lescano AG, Molyneux ME, Winstanley PA, Chimpeni $\mathrm{P}$, Taylor TE, Plowe CV. 2002. Molecular Markers of failure of sulfadoxine-pyrimethamine and chlorproguanil-dapsone treatment of Plasmodium falciparum Malaria. $J$. Infect. Dis., 185(3): 380-388.

Molecular Module, WWARN. 2011. Data management and statistical analysis plan, v1.0.

Moussiliou A, De Tove YS, Doritchamou J, Luty AJF, Massougbodji A, Alifrangis M, Deloron P, Ndam NT. 2013. High rates of parasite recrudescence following intermittent preventive treatment with sulfadoxine-pyrimethamine during pregnanacy in Benin. Malaria J., 12: 195.

Nzila AM, Mberu EK, Sulo J, Dayo H, Winstanley PA, Sibley $\mathrm{CH}$, Watkins WM. 2000. Towards an understanding of the mechanism of pyrimethaminesulfadoxine resistance in Plamodium falciparum genotyping of dihydrofolate reductase and dihydropteroate synthase of Kenyan parasites. Antimicrob. Agents Chemother., 44: 991-996.

Oguche S, Molta NB, Pam SD, Omalu ICJ, Afolabi BM, Odujoko JB, Amajoh CN, Adeniji B, Wuyep VP, Ekanem OJ. 2004. Comparative assessment of the clinical performance of chloroquine and sulfadoxine/pyrimethamine in the treatment of Plasmoduim falciparum infection in Plateau State: an open randomized study of 109 children with acute uncomplicated malaria. Niger. J. Paed., 31(3): 87- 92.

Okeke TA, Uzochukwu BSC, Okafor HU. 2006. An in-depth study of patent medicine sellers perspectives on malaria in a rural Nigerian community. Malaria J., 5: 97.

Omole MK, Onademuen OT. 2010. A survey of antimalarial drug use practices among urban dwellers in Abeokuta, Nigeria. Afr. J. Biomed. Res., 13: 1-7.

Sibley CH, Hyde JE, Sims, PF, Plowe CC, Kublin JG, Mberu EK, Cowman AF, Winstanley PA, Watkins WM, Nzila AM. 2001. Pyrimethamine-sulfadoxine resistance in Plasmodium falciparum. What next? Trends Parasitol., 17: 582588.

Tan KR, Katalenich BL, Mace KE, Nambozi M, Taylor SM, Meshnick SR, Wiegand RE, Chalwe V, Filler SJ, Kamuliwo M, Craig AS. 2014. Efficacy of sulfadoxinepyrimethamine for intermittent preventive treatment of malaria in pregnancy, Mansa, Zambia. Malaria J., 13: 227.

Vallely A, Vallely L, Changalucha J, Greenwood B, Chandramohan D. 2007. Intermittent preventive treatment for malaria in pregnancy in Africa. What's new what's needed. Malaria J., 6: 16.

Warhust D. 2001. New developments: chloroquine resistance in Plasmodium falciparum. Drug Resist. Update, 4: 141.

White N. 2004. Sulfadoxine-pyrimethamine is not working in Malawi. BMJ., 328: 1259.

World Health Organization. 2005. Susceptibility of Plasmodium falciparum to antimalarial drugs: report on global monitoring: 1996-2004. WHO/HTM/ MAL/2005.1103.

World Health Organization. 2010. Guidelines for the Treatment of Malaria $\left(2^{\text {nd }}\right.$ edn). WHO Press World Health Organization: Geneva, Switzerland; 210.

World Health Organization. 2013. WHO policy brief for the implementation of intermittent preventive treatment of malaria in pregnancy using sulfadoxinepyrimethamine $\left(\right.$ IPT $_{\mathrm{P}}$-SP) -April 2013 (revised January 2014). 